\title{
A Rare Case of Transorbital Penetrating Intracranial Injury by a Screw
}

\author{
Gaurav Sharma ${ }^{1}$ Jitendra Singh Shekhawat ${ }^{1} \quad$ Virendra Deo Sinha $^{1}$
}

\author{
${ }^{1}$ Department of Neurosurgery, Sawai Man Singh Medical College \\ Jaipur, Rajasthan, India
}

Indian J Neurotrauma:2021;18:91-92

Penetrating brain injury (PBI) includes all traumatic brain injuries (TBIs) which are not the result of a blunt mechanism. ${ }^{1}$ PBI is rare and it is considered as severe TBI. Transorbital penetrating intracranial injuries account for $0.04 \%$ of all head injuries. ${ }^{2}$

An 18-year-old male was admitted with history of fall from a truck, leading to a penetrating injury in his left eye from a screw placed on the ground. The screw penetrated through the roof of orbit, causing intracranial injury and dislodgement of bony fragment in right lateral ventricle.

On examination, patient had an extremely painful left eye with perforated globe, periorbital hematoma and complete loss of vision in left eye. His Glasgow coma scale (GCS) score was $15 / 15$ at presentation.

CT brain with orbit ( - Fig. 1) suggested fracture of roof of left orbit with intraorbital herniation of brain tissue through the deficient roof. Blowout fracture of floor of the orbit was also seen, with herniated intraorbital contents into the left maxillary sinus. CT brain ( - Fig. 2 ) suggested anterior interhemispheric bleed, and bifrontal hemorrhagic contusions with blood in bilateral lateral ventricles. Bony chip was seen in the right lateral ventricle with air droplet.
Address for correspondence Gaurav Sharma, MCH, Department of Neurosurgery, Sawai Man Singh Medical College, Jaipur 302004 , Rajasthan, India (e-mail: dr.gaurav_87@yahoo.co.in).

In civilian accidents, most penetrating cranial injuries are low-velocity type, which are caused by knives, nails, spikes, iron rods, pencil, scissors, or keys. Pathophysiology depends on the kinetic energy and trajectory of the object through the brain. Lower velocity objects produce a track of primary tissue damage, resulting in focal localized brain parenchymal injury.

CT scan is useful as it can readily determine the extent of intraparenchymal injury, locate the foreign body, detect trajectory, and identify bony defects in the skull. MRI brain is useful in nonmetallic foreign body injuries.

A patient can develop complications such as brain abscess, encephalitis, meningitis, scalp sepsis, and vascular complications such as pseudoaneurysm; posttraumatic arteriovenous malformation, although uncommon, can occur following penetrating head injury. ${ }^{3}$

Initial emergency treatment involves maintenance of airway, breathing and circulation with local hemostasis. Broad-spectrum antibiotics should be started. Surgery is the definitive treatment with goal of surgery being removal of foreign body and bony fragments with debridement of scalp tissue, cranium, dura, and brain parenchyma along with watertight closure of dura (primarily or with pericranial
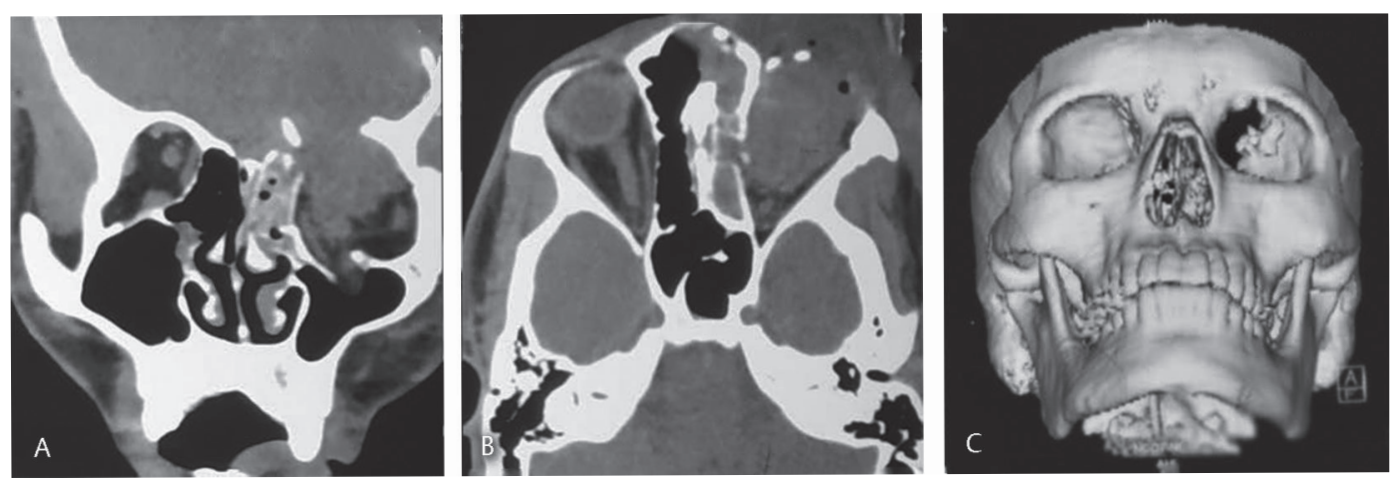

Fig. 1 (A) Coronal section showing fracture of roof and floor of orbit with herniation of brain in left orbit. (B) Axial cut showing fracture of medial wall of orbit with intraorbital air droplet. (C) 3D CT reconstruction showing fracture of roof of orbit.

published online

October 9, 2020
DOI https://doi.org/

$10.1055 / \mathrm{s}-0040-1718241$

ISSN 2277-954X.
(C)2020. Neurotrauma Society of India.

This is an open access article published by Thieme under the terms of the Creative Commons Attribution-NonDerivative-NonCommercial-License, permitting copying and reproduction so long as the original work is given appropriate credit. Contents may not be used for commercial purposes, or adapted, remixed, transformed or built upon. (https://creativecommons.org/licenses/by-nc-nd/4.0/).

Thieme Medical and Scientific Publishers Pvt. Ltd. A-12, 2nd Floor, Sector 2, Noida-201301 UP, India 

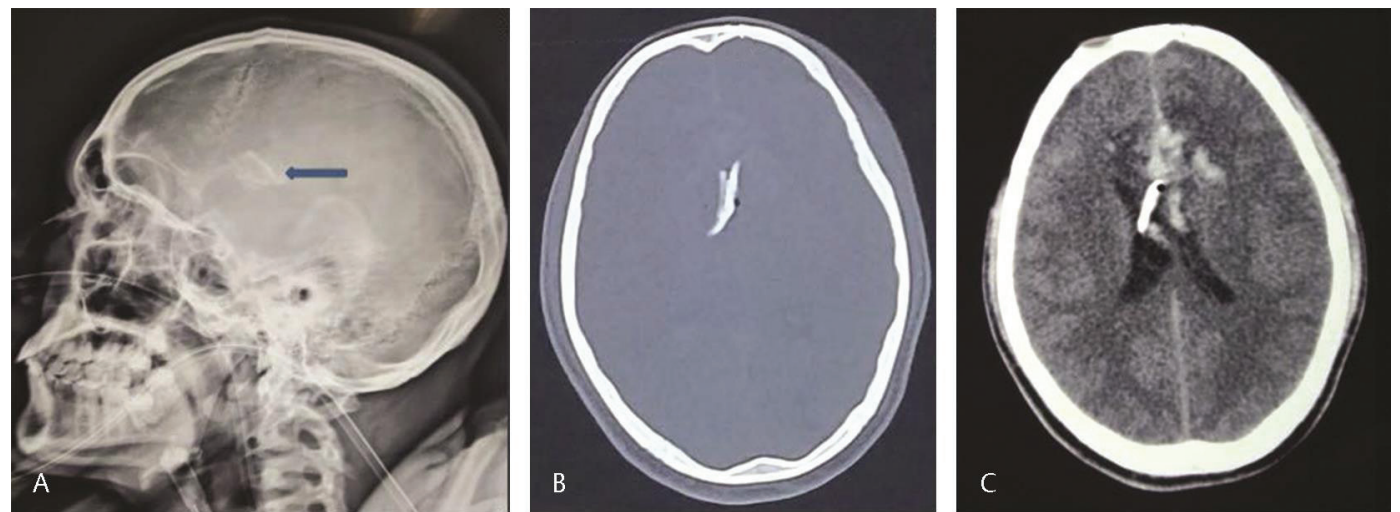

Fig. 2 (A) X-ray skull lateral view showing fracture segment. (B) CT brain bone axial cuts showing bony segment with droplet of air in midline. (C) Noncontrast CT brain showing intraventricular hemorrhage IVH and interhemispheric bleed with frontal contusions. Bony segment is seen in right lateral ventricle.

patch, temporalis fascia). ${ }^{4}$ Permanent neurologic deficit associated with such low-velocity penetrating wounds is determined by the degree and location of the initial injury, timing of operative intervention, and avoidance of delayed secondary injury.

\section{Conflict of Interest}

None declared.

\section{References}

1 Esposito DP, Walker JP. Contemporary management of penetrating brain injury. Neurosurg Q 2009;19:249-254

2 Paiva WS, Saad F, Carvalhal ES. De Amorim RL, Figuereido EG, Teeixera MJ. Transorbital stab penetrating brain injury. Report of a case. Ann Ital Chir 2009;80(6):463-465
3 Peek-Asa C, McArthur D, Hovda D, Kraus J. Early predictors of mortality in penetrating compared with closed brain injury. Brain Inj 2001;15(9):801-810

4 Kelly DF, Nikas DL, Becker DP, Diagnosis and treatment of moderate and severe head injuries in adults. In Youmans JR, ed. Neurological Surgery. 4th ed. Philadelphia: WB Saunders; 1996:1618-718 